\title{
A Geometric and Mechanical Description of The Talus and Cochlea Tibiae in Horse and $O x$
}

\author{
$\odot$ Fatma ISBILIR $^{3}, \star$, ๑ A. Burcu CELIK ${ }^{2}, \odot$ Kadri ARSLAN ${ }^{1}$, \\ ๑ Betul BULCA ${ }^{1}$, ๑ Bahri YILDIZ ${ }^{3}$
}

\begin{abstract}
1Department of Maths, Faculty of Art and Science, Bursa Uludag University, 16059, Nilufer, Bursa, Turkey, 2Department of Mechanical Engineering, Institute of Science, Bursa Uludag University, 16059, Nilufer, Bursa, Turkey, 3Department of Anatomy, Faculty of Veterinary Medicine, Bursa Uludag University, 16059, Nilufer, Bursa, Turkey
\end{abstract}

Received 02-10-2020 Accepted 29-06-2021

\begin{abstract}
In this study, geometrical and mechanical identification of the talus and cochlea tibiae in horse and ox is presented. The shape of the expressed bones of these animals can be considered as rotational surfaces of planar curves. The model is established based on the bolt-nut mechanism while interpreting the relationship between talus and tibiae, and describing geometrical differences between ox and horse in functional anatomy. The results obtained from the geometric and mechanical data have led to the conclusion that lateral and friction forces applied on talus and cochlea tibiae of the horse are higher than that in ox. According to these results, the data obtained helps the horses to stand longer. Keywords: Talus, tarsal joint, stay apparatus, geometric modelling, mechanical fasteners.
\end{abstract}

\section{Introduction}

The tarsal joint is a joint consisting of the distal end of the calf bones, the proximal end of the metatarsal bones, and between these bones, in varying numbers depending on animal species, tarsal bones arranged in three rows. Tarsocrural (talocrural) articulation is the first articulation in this joint. ${ }^{1,2}$ The tarsocrural joint (articulatio tarsocruralis) is a typical ginglymus joint formed by the trochlea of talus, the cochlea of tibiae and the malleolus of fibula (or malleolar bone of ox). The distal end of the tibiae is similar to a three-pronged (two sides, one middle) roller which is called cochlea tibiae., ${ }^{2,3}$ At the distal end of the tibiae, the intermediate ridge of cochlea tibiae is oblique to the median axis of the body in the horse while it is parallel in the ox. Talus is a pulley-like bone. The upper side of the talus takes the name trochlea tali and articulates with cochlea tibiae. ${ }^{1}$ Talus in the ox is similar to two pulleys standing in a row. The upper one is called trochlea tali proximalis and the lower one is trochlea tali distalis. ${ }^{2}$ The trochlea consists of two oblique ridges with a deep groove between them in the horse. These ridges curve spirally from dorsomedial to dorsolateral direction with the angle of 12 to 15 degrees with a sagittal plane. The talus has a proximal trochlear surface shaped to fit the tibiae.1 In the horse, the trochlear ridges are orientated obliquely in a mediolateral direction thus allowing a forward and outward movement of the digit during flexion of the tarsus. ${ }^{4}$

Related to cochlea tibiae, trochlea tali is oblique to the median axis of the body in the horse but is parallel to the median axis of the body in the ox. In ox, the talus is longer and slenderer than that in the horse. ${ }^{3}$ Talus in the ox is similar to two pulleys standing in a row.

the upper one is called trochlea tali proximalis lower trochlea tali distalis. ${ }^{2}$ Even cursory examination of the tarsal skeleton is sufficient to make it clear that while free movement is allowed at the tarsocrural joint, there can be almost no play at any other level. 5,6

\footnotetext{
* Corresponding author: Uludag University, Faculty of Veterinary Medicine, Department of Anatomy, 16059 Nilüfer, Bursa, Turkey. Phone number: +9022429412 26 E-mail adress: fatmagurler@uludag.edu.tr
} 
Geometric modeling is a branch of applied mathematics and computational geometry that provides methods and algorithms for the mathematical identification of objects. The geometric modeling of anatomical morphologies has been very useful for visualizing complex 3D forms. Computer models do not only provide a tool for visualizing complex morphology derived from 2D tissue outlines but may also permit mathematical modeling of growth or functional properties.7,8,9,10,11

Power screws have an important role in mechanical engineering. They are used to convert the rotary motion of the nut or screw concerning the slow linear motion of the coupling element along the screw axis. The goal of many power screws is to achieve a great mechanical advantage in lifting weights. 12,13

This study was designed to develop a modeling technique for the bone surface of talus and cochlea tibiae in horse and ox. The geometrical and mechanical determination of the talus and cochlea tibiae in horse and ox have been examined. For the study, the bone surfaces of these animals have been considered as a rotational surface of a planar curve. The movements of these bone surfaces are interpreted mechanically as a bolt/nut relationship. Consequently, certain stress calculations have been generated and presented here by using this geometrical model.

\section{Materials and Methods}

Bones used for anatomy lesson student applications were used. For this reason, ethics

committee approval was not obtained. Statistical study is not necessary for the purpose of

the study. The talus and tibiae bones of a total of 10 animals, 5 ox and 5 horses, were used.

Geometric work: In this study, a surface of revolution of a certain regular curve was defined. Firstly, a definition of a regular curve in $\mathrm{n}$-dimensional Euclidean space was given, followed by the definition of R3.

Definition 1. Let $\rho:(a, b) \rightarrow R^{n}$ be a function where $(a, b) \subset R \quad$ is an open interval. We write $\rho(t)=\left(\rho_{1}(t), \rho_{2}(t), \ldots, \rho_{n}(t)\right)$, where each $\rho_{i}, 1 \leq i \leq n$ is an ordinary real-valued function of a real variable. We say that $\rho$ is differentiable if and only if each $\rho_{i}$ is differentiable ${ }_{2}$ $1 \leq i \leq n$. Similarly $\rho$ is piecewise differentiable if and only if $\rho_{i}$ is piecewise differentiable $e_{2 m} 1 \leq i \leq n$.

A (parametrized) curve $R^{n}$ can be considered a (piecewise) differentiable function $\rho:(a, b) \rightarrow R^{n}$ where $(a, b)$ is an open interval in $R$. The velocity $\rho$ is given by $\rho^{\prime}(t)=\left(\rho_{1}^{\prime}(t), \rho_{2}^{\prime}(t), \ldots, \rho_{n}^{\prime}(t)\right)$. If $\rho^{\prime}(t) \neq \overrightarrow{0}$ then $\rho$ is said to be regular. ${ }^{6}$
The equations used in the geometric work and their definitions are given in Table 1.

Table 1. Geometric working equations and definitions.

\begin{tabular}{l|l}
\hline$M: x(t, s)=\left(\rho_{1}(t), \rho_{2}(t) \cos (s), \rho_{2}(t) \sin (s)\right)$ & $\begin{array}{l}\text { Definition 2: Let } \rho:(a, b) \rightarrow R^{3} \text { be a regular curve is } R^{3} \\
\text { given with the parametrization } \rho(t)=\left(\rho_{1}(t), \rho_{2}(t), 0\right) . \\
\text { When } \rho \text { revolves in } R^{3} \text { around the x-axis the resulting point } \\
\text { set } M \text { is defined by and is called the surface of revolution } \\
\text { generated by the profile curve } \rho \text {. The x-axis is called the axis } \\
\text { of revolution. }\end{array}$ \\
\hline $\operatorname{plot3d}\left(\left[\rho_{1}(t), \rho_{2}(t) * \cos (s), \rho_{2}(t) * \sin (s)\right] J=a . b, s=c . d\right) ;$ & $\begin{array}{l}\text { In the present study, we consider the talus and cochlea tibiae of } \\
\text { horse and ox as a part of the surface of revolution of a curve } \\
\rho(t)=\left(\rho_{1}(t), \rho_{2}(t), 0\right) . \text { We use the following Maple } \\
\text { command to draw the given surface. }\end{array}$ \\
\hline
\end{tabular}

Mechanical Work: In engineering, it is a good way to disassemble a bolted joint to parts, in a way that it can easily be reassembled again. The main job of a bolted joint is to keep the clamped parts together. Another function is the movement by providing power transmission. There are several methods to tighten a bolted joint. Torque-controlled and angle-controlled tightening are the most widespread methods. With torque-controlled tightening, the amount of tightening force that is provided by the torque is transferred to the fastener. Angle-controlled tightening uses the theoretic relationship between the linear deformation of the bolt over the pitch of the thread and the angle of rotation of the bolt when it is tightened. This is done by tightening the bolted joint enough to ensure full contact between the surfaces.11 The friction coefficient, which is symbolized with, for the bolted joint has a high influence on the tightening torque needed. Friction is the result of the mechanical resistance during motion. As a result of this, there is less gained mechanical energy. A low friction coefficient will result in an assembly that tends to lose clamping force since the friction is too low to keep a locking effect. Furthermore, low friction causes more inaccurate tightening, since the scatter in torque provided by the tightening tool(s) will have a larger impact on the clamping force.11 The greater the initial tightening, the greater the frictional force that must be overcome to initiate loosening. 13

\section{Calculation of tightening torque}

Torque-controlled is one of the prevalent methods used for tightening. To provide the necessary lateral tightened force FLateral, the related torque (moment) has to be calculated. The total tightening torque, which yields the twisting moment MT, is caused by twisting force FTwist that is applied at a distance $\mathrm{L}$ from the axis of torque. The total thread torque $\mathrm{M} 1$ is a result of weight force $\mathrm{FW}$ on threads. The thread friction force FFThread torque M2 is caused by nut friction force FFNut where it arises at nut's outside diameter interface $\mathrm{R}$.

Angle-controlled tightening is the other common method to fasten. In this study, two types of angle profiles are mentioned. One of these is the metric profile bolt, used 
for locking, which has a special tightening ability with low torque values. The other type is the buttress-shaped trapeze profile bolt which is used as a movement bolt because low friction forces and stress values occur at the bolt/nut interface through the angle value.14,15,16 The greater the helix angle (i.e., the greater the slope of the inclined plane), the greater is the loosening tendency. Thus, a coarse thread tends to loosen more easily than a fine thread.13

The lateral tightening force $\mathrm{x}$ is as seen in figure 1 .

The equations used to calculate the tightening torque are presnted in table 2 .

Table 2. Tightening torque calculation equations and definitions

\begin{tabular}{|l|l|}
\hline $\tan (\alpha)=\frac{P}{\pi D_{2}}$. & $\begin{array}{l}\text { P, termed the pitch, gives the road taken in around. The thread } \\
\text { torque is working at the mean diameter } \mathrm{D} 2 \text { with the helix angle } \\
\text { of the thread } \alpha \text { in the perpendicular direction to the axis. }{ }^{14}\end{array}$ \\
\hline$\mu^{\prime}=\frac{\mu}{\cos (\beta / 2)}$. & $\begin{array}{l}\text { Depending on the peak (metric) angle variable } \beta \text {, the friction } \\
\text { coefficient is defined as it is on the size. }\end{array}$ \\
\hline$\gamma^{\prime}=\tan ^{-1} \mu^{\prime}$. & $\begin{array}{l}\text { Using the friction angle } \gamma=\tan \mu \text { one can get the angle of } \\
\text { friction force as it is on the side. }\end{array}$ \\
\hline$F_{W}=F_{L} \tan \left(\alpha+\gamma^{\prime}\right)$. & $\begin{array}{l}\text { To find the lateral tightening force, the equation can be written } \\
\text { as on the side. }\end{array}$ \\
\hline$F_{F \text { nnut }}=\mu^{\prime} F_{L}$. & $\begin{array}{l}\text { Using lateral force, nut's surface friction force can be estimated } \\
\text { as on the side. }\end{array}$ \\
\hline$F_{R}{ }^{2}=F_{W}{ }^{2}+F_{L}^{2}$ & $\begin{array}{l}\text { To calculate friction force Exfloosd, thread surface reaction force } \\
\text { Fr should be estimated firstly as on the side. }\end{array}$ \\
\hline$F_{F T h r e a d}=\mu^{\prime} F_{\text {Reaction }}$ & Then the following relationship holds. \\
\hline$M_{A}=M_{\text {TWist }}=M_{1}+M_{2}$ & $\begin{array}{l}\text { The torque is determined concerning the longitudinal axis A. } \\
\text { Based on our model, the twisting moment equation can be } \\
\text { improved. }\end{array}$ \\
\hline
\end{tabular}

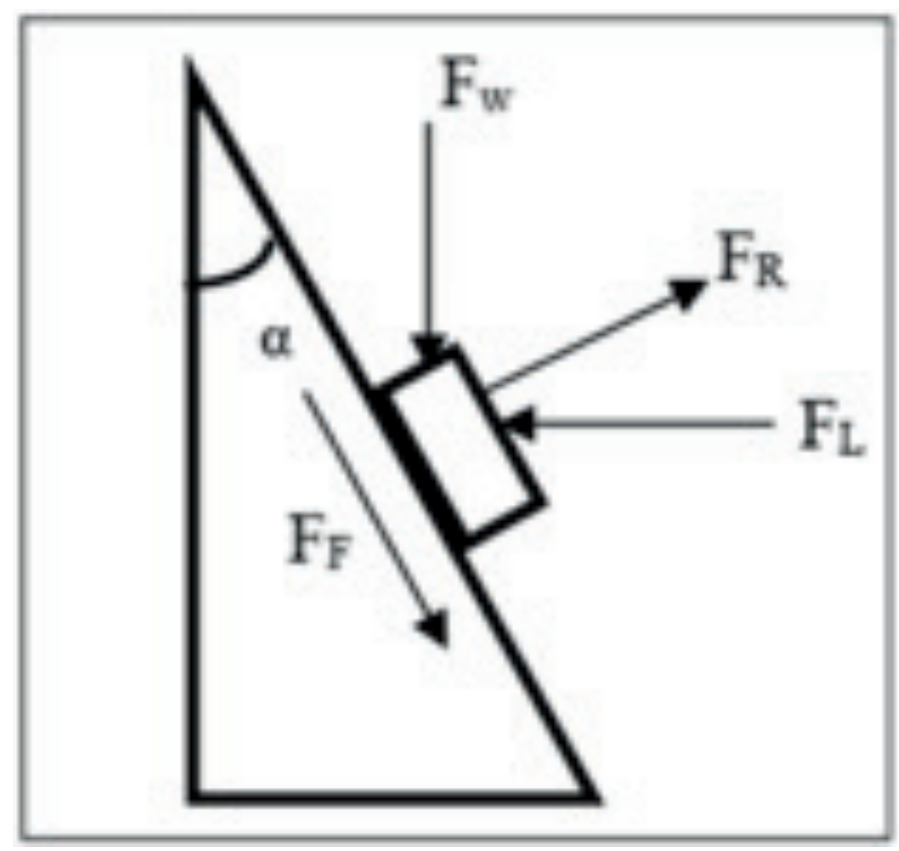

Figure 1. Force Analysis

FL, lateral tightened force, FW, weight force on threads, FR thread surface reaction force, FF, thread friction force, $\alpha$, bolt/nut interface through the helix angle value.

\section{Calculation of Static Stress}

At the bolt/nut mechanism, through external vertical and horizontal forces, the shaft is subjected to compressive stresses that can be calculated by the equations given in table 3.
Table 3. Equations and definitions used in calculation of static stress.

\begin{tabular}{|c|c|}
\hline$\sigma=\frac{F}{A}=\frac{F_{\text {LIIRRAL }}}{\frac{\pi}{4} D_{1}^{2}}$ & $\begin{array}{l}\text { At bolthut mechanis, through extemal vertical and horizontal } \\
\text { forces, hhe shaft is exposed to compressive stresses which can } \\
\text { be callulated. }\end{array}$ \\
\hline$\tau=\frac{M_{b}}{W_{b}}=\frac{F_{T W S I} \times L}{\frac{\pi}{16} D_{1}^{3}}$ & $\begin{array}{l}\text { Where } D i \text { is the minor diameter of the bolt. While tightening, } \\
\text { the bolttrut shaft is subjected to torsional stress. This stress can } \\
\text { be estimated by the static classic equation, where } D i \text { is the } \\
\text { thread root diameter. }\end{array}$ \\
\hline$\sigma_{E_{q}}=\sqrt{\sigma^{2}+3 \times \tau^{2}}$ & $\begin{array}{l}\text { Herciin, since nomal and shear stresses are together, the } \\
\text { maximum shape deformation hypothesis equation found in the } \\
\text { literature can be used. }\end{array}$ \\
\hline$\sigma_{E_{q}}=\frac{3.9 \times F_{L A \pi R A L L}}{\pi P D_{1}}$ & $\begin{array}{l}\text { Thread equivalent stress consiststs of compression, bending, and } \\
\text { shear stresses during tightening. Thus, equivalent stress can be } \\
\text { estimated on the side equation. }\end{array}$ \\
\hline$P=\frac{F}{\pi D_{2}\left(D-D_{1}\right)}$ & $\begin{array}{l}\text { The touching surficese apply pressure to each other during } \\
\text { tightening. Therefore, some shape deformations occur on thread } \\
\text { surfaces due to the size of the pressure and surface area. That } \\
\text { simple equation can be used alongside. }\end{array}$ \\
\hline
\end{tabular}

As a result of the twisting moment, where is the thread root diameter, experiences the greatest distortion of any points on the entire surface. 13

If the equivalent stress is excessive, shape deformations occur on the thread or shaft, whichever is the weaker point.13 where $\mathrm{D}$, and are the major diameter, thread root diameter and mean diameter of the bolt, respectively.

Further, it is possible to evaluate the notch effect of the bolt/ nut mechanism. Sudden section changes, such as a sharp angle, cause an increase in stress even though estimated average stress may be at safety intervals. At the notch region, stress reaches peak values and causes shape deformation.

In engineering, a mathematical model has been developed for comparing functionally two different geometry of talus and cochlea tibiae. The model is established based on the bolt-nut mechanism while interpreting talus and cochlea tibiae relationships and describing the difference between ox and horse's tibiae and talus geometry. The reason for using bolt-nut stress and force analysis (Figure 1) equations herein is that tibiae of the os tarsi centrale (os centroquartale in ox) fastened with talus for increased load carrying capacity, and to support the movement by providing power transmission. In our model, torque-controlled and angle-controlled tightening methods are used together.

Horse peak angle resembles the metric profile as a locking bolt. Ox peak angle's trapeze profile resembles the buttress bolt mechanically.

To estimate equations, critical values, where relevant, are measured with a compass and 3D Builder Windows Software. Thus, 3D Builder Windows Software results (Table 1) are used here to easily compute the results. Critical parameters are defined as follows. D (Figure 2, Figure 3) is the outside diameter or the distance from the center of the medial depression for ligamentous attachment on the talus to the center of the dorsal part of the lateral ridge of the trochlea. ( Figure 2, Figure 3), is the mean diameter or the length between the center of the medial depression for ligamentous attachment on the talus (proximal trochlea in ox) and caudodorsal surface about 29-35 mm. (Figure 2, Figure 3), is the minor diameter; the length between 

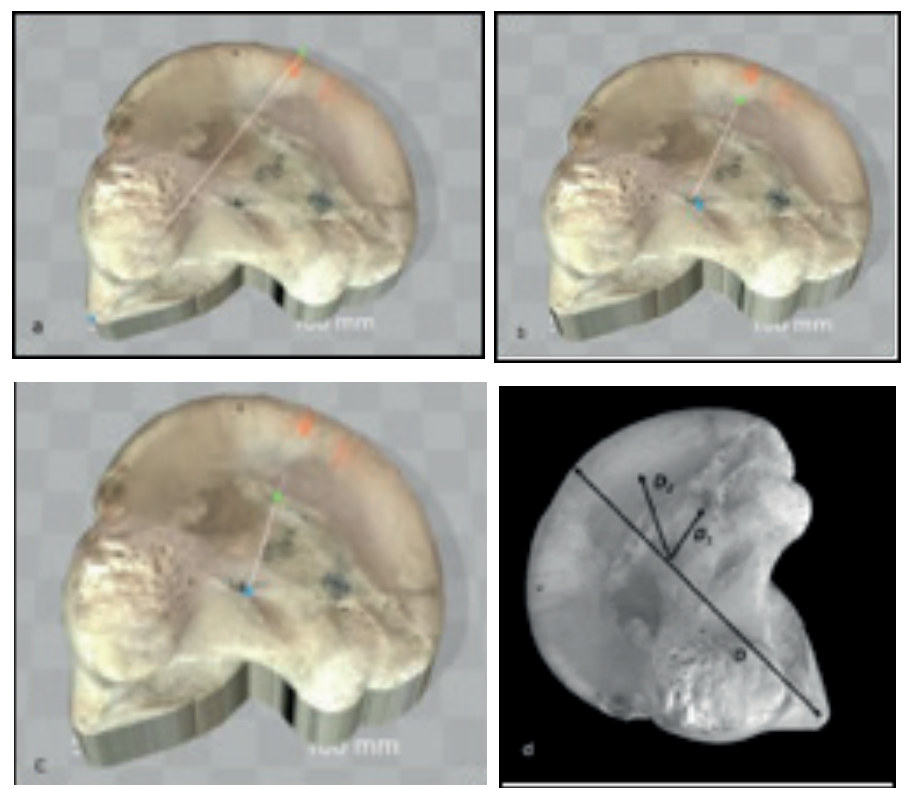

Figure 2. The values of D, D1 and D2 at right talus of horse. Medial view.

$\mathrm{D}$ is the outside diameter or the distance from the center of the medial depression for ligamentous attachment on the talus to the center of the dorsal part of the lateral ridge of the trochlea. is the minor diameter; the length between the center of the medial depression for ligamentous attachment on talus and caudodorsal surface. , is the mean diameter or the length between the center of the medial depression for ligamentous attachment on the talus and caudodorsal surface.
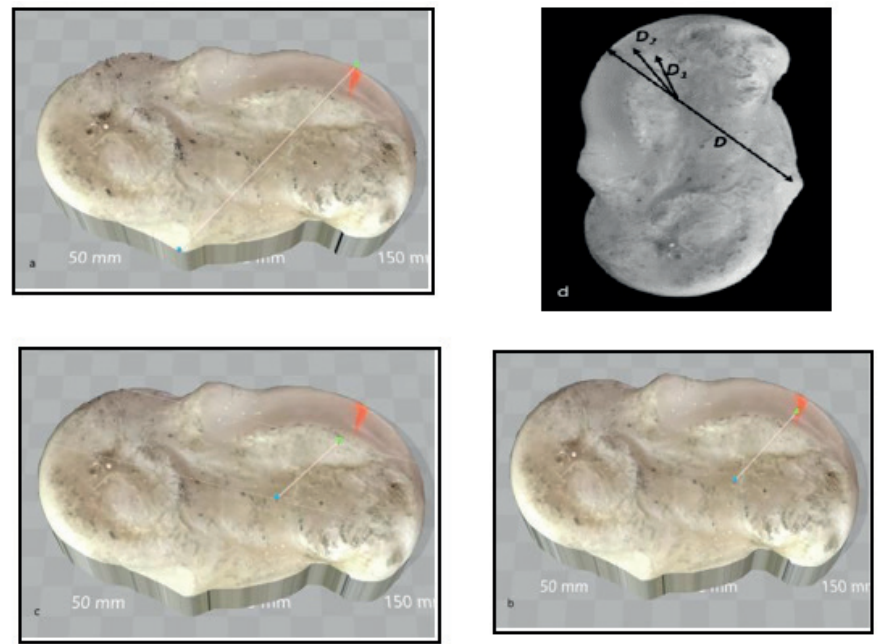

Figure 3. The values of D, D1 and D2 at right talus of ox. Medial view.

$\mathrm{D}$ is the outside diameter or the distance from the center of the medial depression for ligamentous attachment on the talus to the center of the dorsal part of the lateral ridge of the trochlea. is the minor diameter; the length between the center of the medial depression for ligamentous attachment on proximal trochlea and caudodorsal surface. , is the mean diameter or the length between the center of the medial depression for ligamentous attachment on the proximal trochlea and caudodorsal surface.

the center of the medial depression for ligamentous attachment on talus (proximal trochlea in ox) and caudodorsal surface about $22-30 \mathrm{~mm}$. is the peak angle, between the
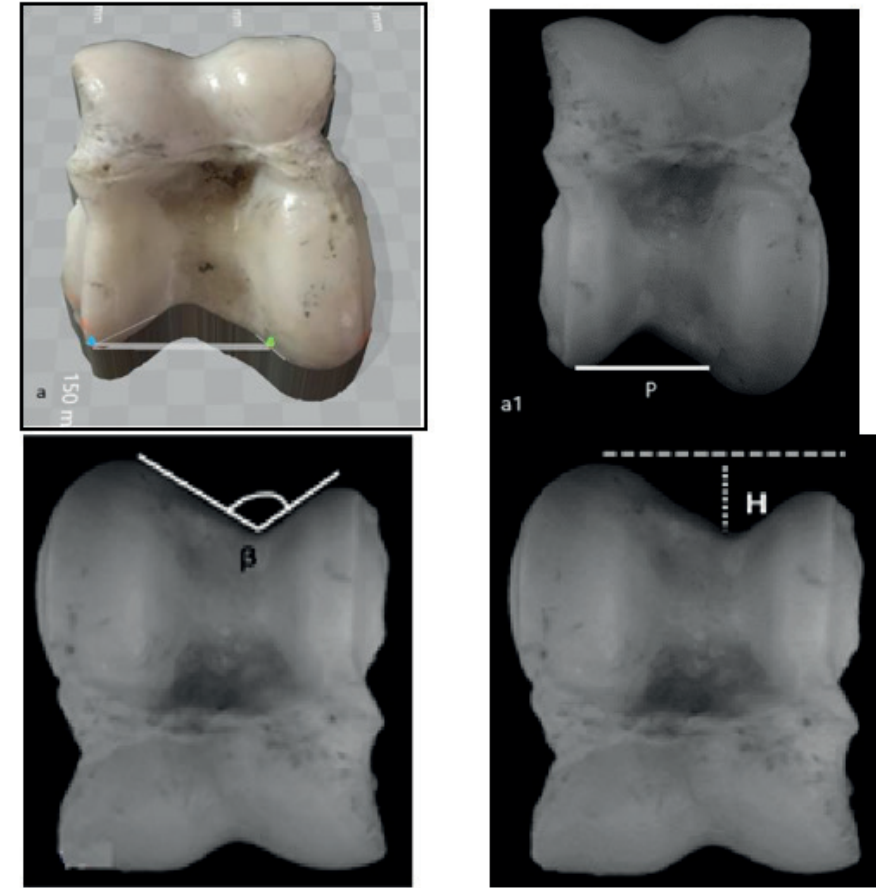

Figure 4. The values of $\mathrm{P}(\mathrm{a}, \mathrm{a} 1), \mathrm{\nabla}$ and $\mathrm{H}$ at right talus of ox. Cranial view.

is the peak angle, between the inner margins of the medial and lateral ridges of talus. $\mathrm{P}$ is pitch, which is the distance between the outer edges of the lateral and medial ridges of talus. $\mathrm{H}$ is the distance between the apex of the high protrusion of the trochlea and the trough area between the two protrusions of the trochlea.
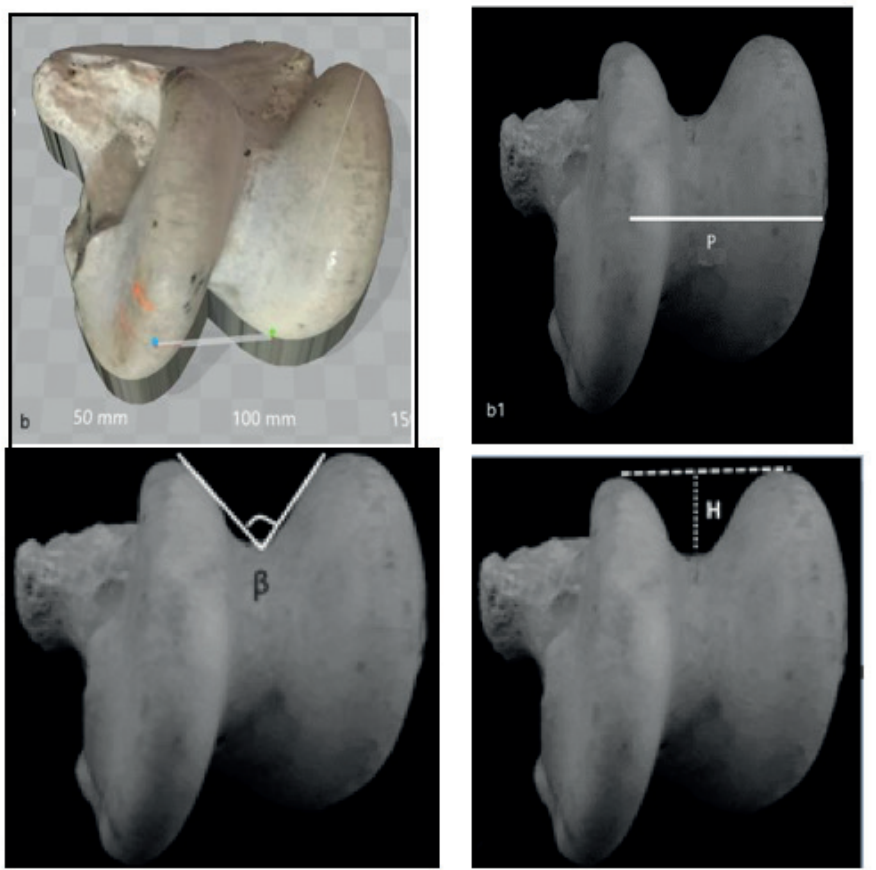

Figure 5. The values of $\mathrm{P}(\mathrm{b}, \mathrm{b} 1), \mathrm{Q}$ and $\mathrm{H}$ at right talus of horse. Cranial view.

is the peak angle, between the inner margins of the medial and lateral ridges of talus. $\mathrm{P}$ is pitch, which is the distance between the outer edges of the lateral and medial ridges of talus. $\mathrm{H}$ is the distance between the apex of the high protrusion of the trochlea and the trough area between the two protrusions of the trochlea. 
inner margins of the medial and lateral ridges of talus, which is measured with digital compass. Consequently, the tibial length $\mathrm{mm}$., the friction coefficient (which are the same both horse and ox). Each leg of horse and ox is loaded $150 \mathrm{~kg}$ and converted to force by multiplying with the acceleration of gravity, 9.81 .

Also, the points that correspond to talus and cochlea tibiae in our model referred to as P (Figure 4, Figure 5), are termed the pitch, which is the distance between the outer edges of the lateral and medial ridges of talus.
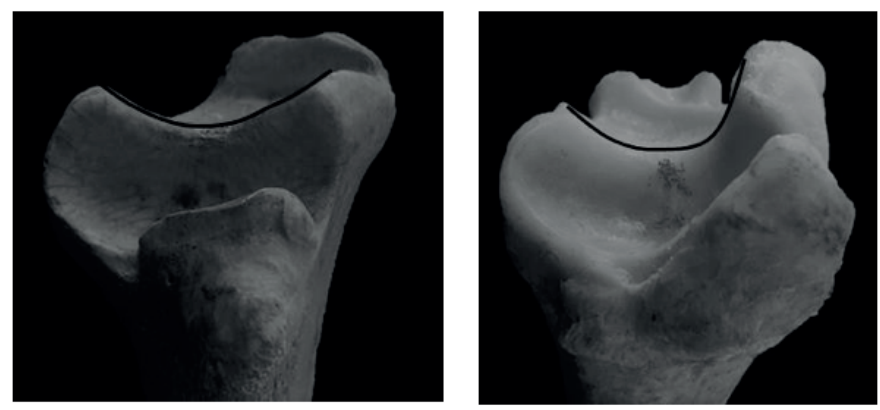

Figure 6. Cochlea tibiae of horse and ox Cranial view.

Table 4. Measurement of critical values on talus and tibiae surfaces by 3D Builder Windows Software of horse and ox.

\begin{tabular}{lccccccc}
\hline \multicolumn{7}{c}{ 3D Builder (mm) } \\
& $\mathrm{P}$ & $\mathrm{D}_{1}$ & $\mathrm{D}_{2}$ & $\mathrm{D}$ & $\beta\left(^{\circ}\right)$ & $\mathrm{R}$ & $\mathrm{L}$ \\
& & & & & & & \\
\hline Horse & 32.69 & 20.84 & 28.27 & 41.55 & 60 & 14.00 & 30.00 \\
Ox & 44.29 & 28.81 & 32.00 & 43.92 & 34 & 16.00 & 30.00
\end{tabular}

$\mathrm{P}$, termed the pitch. $\mathrm{D}$ is the outside diameter or the distance from the center of the medial depression for ligamentous attachment on the talus to the center of the dorsal part of the lateral ridge of the trochlea. is the minor diameter; the length between the center of the medial depression for ligamentous attachment on talus (proximal trochlea in ox). is the mean diameter or the length between the center of the medial depression for ligamentous attachment on the talus (proximal trochlea in ox). is the peak angle, between the inner margins of the medial and lateral ridges of talus, Nut's outside diameter interface $\mathrm{R}$, the tibial lengt $\mathrm{L}$, the friction coefficient (which are the same both horse and ox).
Table 5. Measurement of critical mean values (5 patterns) on talus and tibiae surfaces by caliper of horse and ox.

\begin{tabular}{lccccccc}
\hline \multicolumn{7}{c}{ Composing stick $(\mathrm{mm})$} \\
\hline & $\mathrm{P}$ & $\mathrm{D}_{1}$ & $\mathrm{D} \mathrm{D}_{2}$ & $\mathrm{D}$ & $\beta\left(^{\circ}\right)$ & $\mathrm{R}$ & $\mathrm{L}$ \\
\hline Horse & 32.4 & 22.00 & 29.54 & 42.00 & 60 & 14.00 & 30.00 \\
Ox & 44.00 & 29.26 & 34.56 & 44.60 & 34 & 16.00 & 30.00 \\
\hline
\end{tabular}

P, termed the pitch. D is the outside diameter or the distance from the center of the medial depression for ligamentous attachment on the talus to the center of the dorsal part of the lateral ridge of the trochlea. is the minor diameter; the length between the center of the medial depression for ligamentous attachment on talus (proximal trochlea in ox). is the mean diameter or the length between the center of the medial depression for ligamentous attachment on the talus (proximal trochlea in ox). is the peak angle, between the inner margins of the medial and lateral ridges of talus, Nut's outside diameter interface $\mathrm{R}$, the tibial lengt $\mathrm{L}$, the friction coefficient (which are the same both horse and ox).

Table 6. Lateral and friction loads angles.

\begin{tabular}{lccccc}
\hline & $\alpha$ & $\beta\left(^{\circ}\right)$ & $\mu$ & $\mu^{\prime}$ & $\gamma^{\prime}$ \\
\hline Horse & 20.20 & 60 & 0.3 & 0.346 & 19.10 \\
Ox & 24.00 & 34 & 0.3 & 0.313 & 17.41
\end{tabular}

The friction coefficient (which are the same both horse and ox). The helix angle of the thread in the perpendicular direction to the axis.14 Depending on the peak (metric) angle variable, the friction coefficient is defined by: Using the friction angle one can get the angle of friction force by: .

Table 7. Comparison of forces.

\begin{tabular}{|c|c|c|c|c|c|c|}
\hline & \multicolumn{6}{|c|}{ (N) } \\
\hline & $F_{\text {Weight }}$ & $\mathrm{F}_{\text {Lateral }}$ & $F_{\text {Reaction }}$ & FFThread & $F_{F N u t}$ & $\mathrm{~F}_{\text {Twist }}$ \\
\hline Horse & 1471.5 & 1797.82 & 2323.24 & 803.84 & 622.04 & 919.44 \\
\hline Ox & 1471.5 & 1668.50 & 2224.68 & 696.32 & 522.24 & 1105.38 \\
\hline
\end{tabular}

Lateral tightened force FLateral, the related torque (moment) has to be calculated. The total tightening torque, which yields the twisting moment MT, is caused by twisting force FTwist that is applied at a distance $\mathrm{L}$ from the axis of torque. The total thread torque M1 is a result of weight force FWeight on threads. The thread friction force FFThread torque M2 is caused by nut friction force FFNut where it arises at nut's outside diameter interface R. FReaction, thread surface reaction force FR. 
Table 8. Comparison of stresses.

\begin{tabular}{|c|c|c|c|c|c|c|}
\hline \multicolumn{7}{|c|}{$\left(\mathrm{N} / \mathrm{mm}^{2}\right)$} \\
\hline & $\tau$ & $\sigma_{\text {comp }}$ & $\sigma$ & $\sigma_{\text {eqshaft }}$ & $\sigma_{\text {eqthread }}$ & $\mathrm{P}$ \\
\hline Horse & 16.03 & 5.30 & 4.34 & 27.95 & 3.27 & 0.97 \\
\hline $\mathrm{Ox}$ & 7.30 & 2.57 & 2.27 & 20.72 & 1.62 & 1.1 \\
\hline
\end{tabular}

At bolt/nut mechanism, through external vertical and horizontal forces, the shaft is exposed to compressive stresses, where D1 is the minor diameter of the bolt. While tightening, the bolt/nut shaft is subjected to torsional stress. This stress can be refered by , where D1 is the thread root diameter.

Herein, since normal and shear stresses are together, the maximum shape deformation

, , calculated for shape deformation on saft and , calculated for shape deformation on thread.

Afterward, thread equivalent stress consists of compression, bending, and shear stresses during tightening refered by .

\section{Discussion and Conclusion}

The previous work of first and second authors was related to anatomical organ modeling.7,8,9,10,11 Some studies have been conducted to evaluate the anatomy of the tarsal joint in horses. In the studies, the normal anatomical features of the joint were defined by radiography and computed tomography. 17,18 Besides, no mechanical and geometrical study was found on this joint. It is the first geometric and mechanical study in this area. The present study is the first presents a modeling technique for the bone surface of ox and horse of talus and cochlea tibiae, respectively. In the mechanical study, the measured values of ox and horse of talus and cochlea tibiae and the surface models formed according to the geometrical formulas were considered, and the accuracy of the 3D graphics was confirmed by the real-life photographs. Furthermore, we plot their graphics using the Maple 14 program.

According to Table 3 results, the measure of the helix angle has a great value (i.e, the greater the slope of the inclined plane), then the tendency to relax is also too. Thus, coarse threads tend to loosen more easily than fine threads. The power screws are used to convert the rotary motion of the nut or screw for the slow linear motion of the coupling element along the screw axis. The goal of many power screws is to achieve a great mechanical advantage in lifting weights. 13 Concerning this, ox's talus needs more power to stand than horse's. One can be observed in Table 3 that for the horse, applying with $20 \%$ less twisting force (=Torque), $7.2 \%$ more lateral tightening force is achieved than for the ox. According to Table 4 results, as mentioned above, the trapeze profile is good at absorbing stresses. Therefore, ox's equivalent stress values are $50 \%$ less than that for the horse approximately. However, thread surface pressure is $13 \%$ more than for the horse. That means, horse overcomes 13 $\%$ better than ox with shape deformations due to crush resistance between thread surfaces.

It can be seen that there is a good functional relationship between bolt/nut mechanism with cochlea tibiae and talus. Obtained data from the geometric and mechanical analyses showed that lateral and friction forces applied on talus and cochlea tibiae of the horse are greater than that in the ox. Because of the differences between the helix angle and the peak angle, the horse can get more torsional moment by applying less torsional force to stand up than ox.

We also hope that the geometric and mechanical data presented in this study will contribute to the anatomical bone modeling studies in the future.

\section{Acknowledgements.}

We thank Ilker ARICAN and Bayram SUZER for useful comments during this study.

\section{Conflict of Interest:}

The authors declare that they have no conflict of interest.

\section{References}

Getty R. The anatomy of the domestic animals. 5th ed. Volume I, Philadelphia- London- Toronto, WB Saunders Company; 1987.

Bahadır A, Yıldız H. Hareket Sistemi ve İç Organlar. Ezgi Kitabevi. Bursa- Türkiye, 2017.

Nickel R, Schummer A, Seiferle E. The Locomotor System of the Domestic Animals. Volume I. Verlag Paul Parey. Berlin-Hamburg, 1986.

Dyce KM, Sack WO, Wensing CJG. Textbook of veterinary anatomy (Veteriner Anatomi Konu Anlatımı ve Atlas). 4th Ed. Güneș Tip Kitabevleri. Ankara- Türkiye, 2017.

Budras DK, Habel RE. Bovine Anatomy. 14th ed. Hannover-Germany, Schlütersche Verlagsgesellschaft mbH \& Company; 2011.

Gray A. Modern differential geometry of curves and surfaces. CRC Press. Tokyo, 1993.

Coşkun I, Yıldız H, Arslan K. A geometric modeling of dog intestine. It J Anat Embryol. 2007;112(1):27-36.

Ezentaş R, Arslan K, Yıldız H, et al. A Geometric Description of the Urinary Bladder of the Turkish Shepherd Dog (Karabaş). Ann Anat. 2005;187:179-184.

Yıldız B, Arslan K, Yıldız H. A Geometric Description of the Ascending Colon of Some Domestic Animals. Ann Anat. 2001;183:555-557. 
Ylldız H, Yıldız B, Arslan K. A Mathematical Model of the Ascending Colon of the Horse. Ann Anat. 2001;183:551-554.

Yıldız H, Arslan K, Coşkun İ. A Geometric Modelling of dog Intestine. Turk J Vet Anim Sci. 2006;30:483488.

Babalık FC. Makine Elemanları ve Konstrüksüyon Örnekleri. Dora Yayınları. Bursa- Türkiye, 2006.

Juvinall RC, Marshek KM. Fundamentals of Machine Component. 5th ed. John Wiley \& Sons, Inc. USA, 2017.

Mortensen J. Friction Analysis of Bolts. Aalborg Universitet. Esbjerg, 2013.

Ma S, Nemcik J, Aziz N. An analytical model of fully grouted rock bolts subjected to tensile load. Construction and Building Materials. 2013.

Shigley JE. Standard Handbook of Machine Design. 23. The University of Texas at El Paso, Texas; 2004.

Hanson JA, Seeherman HJ, Kirker-Head CA, et al. The role of computed tomography in evaluation of subchondral osseous lesions in seven horses with chronic synovitis. Equine veterinary journal. 1996;28(6):480488.

Huguet EE, Porter EG, Chapman KA, et al. Radiographic anatomy of the equine distal tibia. Vet Radiol Ultrasound. 2020;61(5):497-506. 